\title{
Economic Analysis of Deposit-Refund Systems with Measures for Mitigating Negative Impacts on Suppliers
}

\author{
Daisuke Numata* \\ Kobe University Working Paper Series No.169 \\ December 13, 2004 \\ Revised on June 11, 2005
}

\begin{abstract}
The real-world application of a deposit-refund system, though recommended in various studies, has not caught on. The gap can be attributed to the negative impacts on suppliers caused by the introduction of the system. This aspect has been ignored in previous studies. This paper considers the welfare implications of policies mitigating those impacts.

Using welfare analysis, we consider three mitigation policies in an economy with $n$ number of representative consumers, a representative supplier, and the government. One policy is to let suppliers keep unredeemed deposits, which are the difference between deposits and refunds. Another policy is paying a handling commission to the suppliers. The other policy is subsidizing the initial cost for the collection of materials.

The result can be summarized in three points. First, the government should hold unredeemed deposits when a deposit level is set to be equal to externality. In this case, however, there is a possibility that the negative impacts on suppliers could further deteriorate. Second, whether or not the handling commission is paid does not matter; however, paying a handling commission could increase the burden on the suppliers. Third, subsidizing the initial cost also does not matter, however it is related to fairness among the consumer and the producer.
\end{abstract}

Key Words: Deposit-Refund System, Mitigating Negative Impacts, Unredeemed Deposits, Handling Commission

\footnotetext{
${ }^{*}$ Graduate School of Economics, Kobe University. 2-1 Rokkodai, Nada, Kobe 657-8501, Japan
} E-mail: 027d204e@y02.kobe-u.ac.jp 


\section{Introduction}

In a deposit-refund system, consumers pay deposits that are added to the price and receive refunds when they return the used products. This system is one of the economic instruments used for environmental protection; it combines taxes and subsidies to prevent litter and promote material recovery. Consumers of deposit-refund goods have an incentive to return used products and receive refunds, and a high recovery rate can be attained with low monitoring costs. If consumers dispose of used products in an inappropriate manner, the deposits can be used to recover the externality from the disposed products. Furthermore, since refunds are compensated from deposits, funds for a deposit-refund system are smaller than those for a system offering subsidies for returned used products. ${ }^{1}$

Various studies theoretically ${ }^{2-5}$ show a deposit-refund system to be an optimal fee structure. Also, it is empirically shown to be the most inexpensive policy. ${ }^{6}$ Furthermore, some studies theoretically show that an appropriate deposit-refund system could bring about an improvement in the design for environment(DfE). ${ }^{7,8}$

However, this system can hardly be realized in practice because it negatively impacts suppliers, including manufacturers, wholesalers, and retailers. One report summarized the negative impacts on suppliers in three points: ${ }^{9}$

(a) Increase in collecting cost.

(b) Decrease in sales by adding deposits to price.

(c) Expenses involved in putting collecting systems in place are huge.

Onuma and Saito $(2003)^{10}$ considered the point that a deposit-refund system may increase suppliers' anxiety because it: (b) decreases sales due to the price increase. They conclude that in a partial equilibrium economy of one representative producer and one representative consumer, a deposit-refund system does not always adversely affect the producer.

This paper builds on the study conducted by Onuma and Saito by considering the following three policies for mitigating the negative impacts on suppliers:

(1) Letting suppliers keep unredeemed deposits.

(2) Paying suppliers handling commissions in proportion to the collected products. 
(3) Subsidizing the initial cost for the collection of materials.

Several studies have compared a deposit-refund system with other economic instruments, such as advance disposal fee, recycling subsidy, and recycled content standard. One method for theoretical comparison is to derive conditions for attaining social optimum by matching the marginal conditions of a decentralized economy with those of a social planner $4,11-13$; the other is to compare welfare surpluses. ${ }^{2}$ Empirically, when the cost for waste reduction targets among various policies was simulated, the deposit-refund system was found to be the most efficient instrument. ${ }^{6,14}$ However, the mitigation policies for negative impacts on suppliers have not yet been examined thoroughly. Therefore, there exists a gap between previous studies and actual practice. This paper aims to bridge this gap by pointing out the practical conditions for implementing the deposit-refund system.

Using a partial equilibrium model, we compare the conditions on which these policies successfully mitigate the negative impacts on suppliers. Furthermore, we consider the conditions on which the deposit-refund system with these policies brings about an improvement in social welfare.

This model consists of eight aspects, which are divided by the three resistance mitigating policies. First, the model is divided into two categories on the basis of whether or not suppliers are allowed to keep unredeemed deposits. Next, the model is further divided into two sub-categories on the basis of whether or not the handling commissions are paid. Moreover, the model is further divided on the basis of whether or not the policy to subsidize the initial cost for the collection of materials is introduced. The model assumes the beverage container deposit-refund system; however it could easily be applied to other products as well.

Figure 1 illustrates the model concept wherein suppliers hold unredeemed deposits. When a deposit-refund system is introduced, consumers pay deposits that are added to the price. If they return used containers, they are eligible to receive refunds. Due to the mandatory deposit regulation, suppliers are forced to collect used containers ${ }^{16}$. Uncollected containers inevitably become waste or litter, which causes externality. Deposits of uncollected containers are not refunded, which are called unredeemed deposits. Suppliers hold 
this unredeemed deposits and receive scrap revenue by selling the collected containers in the markets for recyclables. However, in many cases, unredeemed deposits and scrap revenue are not enough to compensate for the expenses incurred by the suppliers. Therefore, the government has to pay the suppliers a handling commission for every container received and has to subsidize the initial cost for collection. The government may charge consumers a lump-sum tax for the payment of handling commissions and for the payment of subsidy for initial cost. On the other hand, the government could confiscate unredeemed deposits from the suppliers. Figure 2 illustrates this situation. In this case, we assume the government can use unredeemed deposits for handling commissions. However, when the government still requires funds, it charges consumers a lump-sum tax.

Table 1 shows practical examples of the present mandatory beverage container depositrefund system in North America and Japan. Unredeemed deposit holders are divided on the basis of whether they are suppliers or the government and on the basis of whether or not the handling commission is paid. "Government" in this table refers to an organization managing the deposit-refund system. This implies not only the government but also a supplier-oriented nonprofit organization or a government-oriented nonprofit organization, which plays a role of a government in the model concept; however British Columbia and Alberta in Canada does not charge a lump-sum tax to consumers, but charge consumers a proportional tax to the sales volume. In this meaning, the government in British Columbia and Alberta does not correspond to the government assumed in this paper's model concept exactly.

Our results have three policy implications. First, we find that the government should hold unredeemed deposits when a deposit level is set to be equal to externality. However, the negative impacts on suppliers may increase. Second, whether or not the amount of handling commission is paid does not matter; however, a large amount succeeds in mitigating the negative impacts on the suppliers. Third, whether or not subsidizing the initial cost also does not matter; however this subsidy has the possibility to make resistance alleviated.

This paper proceeds as follows: The basic structure of the model is presented in the next section. In Section 3, we examine the market equilibrium and derive surpluses to de- 
duce policy implications. Finally, we summarize our conclusions in Section 4. The Appendix shows the method by which to calculate surpluses in each category of the model and the surplus results in each category.

\section{The Model}

Our model is based on Onuma and Saito $(2003)^{10}$; in order to explicitly analyze externality, we increase the number of consumers to $n$ representative consumers, where $n$ is a positive integer more than one. This is a partial equilibrium model in which there are $n$ representative consumers, a representative supplier, and the government. The profit function of this study is changed at the point where handling commissions and the cost of collecting containers are added and unredeemed deposits are subtracted in the case of the government confiscating unredeemed deposits. This helps to analyze the suppliers' resistance alleviating policies. We assume that the government behaves on the basis of the revenue neutral constraint. Mrozek (1997) $)^{15}$ considers a revenue neutral constraint in the deposit-refund system; however, his study does not consider handling commissions. In this paper, the revenue neutral constraint considers handling commissions comprehensively.

\subsection{Before a Deposit-Refund System}

The consumer maximizes the utility function under a budget and resource constraint. The utility function is well-behaved and is given by

$$
U(x, l, M)=u(x)+v(l)+M+z(W),
$$

where $x \in R_{+}, l \in R_{+}, M \in R_{+} . u(x)$ is the utility which is gained from consuming $x$, goods that will be a subject of the deposit-refund system in the next section. $v(l)$ expresses disutility which is a function of labor time, $l$, representing the hours taken to return the containers. The quantity of returned containers, $y$, is assumed to be proportional to $l$, which implies that $y$ is equal to $h l$, where $h>0 . M$ is the amount of numeraire, $z(W)$ is negative externality, and $W$ is aggregate waste, which is equal to $n w . w$ is the result of the difference 
between one representative consumer's consumption, $x$, and the returned containers, $y$. The budget constraint is $p x+M \leq I$, where $p \in R_{+}$is the given price of $x$ and $I$ is the given income of the consumer. The resource constraint is denoted by $x \geq y$, which implies that the returned containers are fewer in number than the purchased goods. However, in practice, the return rate is rarely 100 percent. In order to refrain from finding a corner solution, the case wherein $x>y$ is shown below.

We specify $u(x)$ as $a_{d} x-\frac{1}{2} m_{d} x^{2}$, where the domain of $x$ is set between 0 and $\frac{a_{d}}{m_{d}}, v(l)$ as $-\frac{1}{2} m_{k} h^{2} l^{2}$ and $z(W)$ as $\theta W$, where $a_{d}>0, m_{d}>0, m_{k}>0$. This results in the Lagrangean being

$$
L=a_{d} x-\frac{1}{2} m_{d} x^{2}-\frac{1}{2} m_{k} h^{2} l^{2}+M-\theta W+\lambda(I-p x-M),
$$

where $\lambda$ indicates a marginal utility of income. The consumer can choose $x, l$, and $M$, which derives the necessary conditions for the inverse demand function

$$
\begin{aligned}
& p=a_{d}-m_{d} x \\
& I-p x-M=0
\end{aligned}
$$

and $l$ is equal to 0 , so that $y$ is equal to 0 .

The producer maximizes the profit function, which is assumed as being well-behaved and is given by

$$
\pi(X)=p X-C_{1}(X)
$$

The producer sells $x$ to $n$ consumers; therefore, the supply of the producer is denoted by $n x$, which is expressed as $X . C_{1}(X)$ is the cost of producing and selling $X$, in which it is assumed that $C_{1}^{\prime}>0$ and $C_{1}^{\prime \prime}>0$. Since a representative consumer does not return the containers before a deposit legislation, a representative producer does not expend at all for collecting the containers.

We specify $C_{1}(X)$ as $\frac{1}{2} m_{s x} X^{2}+a_{s x} X+\bar{C}_{1}$, where $m_{s x}>0$ and $a_{s x}>0 . \bar{C}$ is a fixed cost used to establish a beverage sales system.

Since $y$ is equal to 0 , the producer can choose $X$, which derives the first order condition 
for a inverse supply function as

$$
p=m_{s x} X+a_{s x} .
$$

Therefore, the market equilibrium can be described as follows:

$$
\begin{aligned}
x^{*} & =\frac{a_{d}-a_{s x}}{m_{d}+m_{s x}} \\
y^{*} & =0 \\
p^{*} & =\frac{a_{d} m_{s x}+a_{s x} m_{d}}{m_{d}+m_{s x}} \\
M^{*} & =I-\frac{\left(a_{d} m_{s x}+a_{s x} m_{d}\right)\left(a_{d}-a_{s x}\right)}{\left(m_{d}+m_{s x}\right)^{2}}
\end{aligned}
$$

\subsection{After a Deposit-Refund System}

In a deposit-refund system, the consumer pays deposits added to the price. On returning the containers, the consumer receives a refund that is equal to the amount of the deposit. This model assumes that consumers maximize utility knowing that they can get a refund by returning the containers. There are several discussions with regard to the deposit-refund system. One argument is that consumers do not consider the refunds they are eligible to receive on return of the containers. This leads us to analyze the deposit-refund system by distinguishing purchase behavior from return behavior. Another argument is that consumers purchase products knowing that they can get a refund on returning the containers. This leads us to analyze the above-mentioned assumption. As Bohm $(1981)^{1}$ suggests, it is not so important to know which argument is correct. The application of each argument depends on the consumer and product type. This paper follows the latter argument because it can be easily analyzed. In practice, this type of consumer behavior is typically seen in deposit-refund systems for malt beer case in Europe. Therefore, a representative consumer is assumed to maximize utility under an income, which includes refunds. The budget constraint is therefore given by

$$
(p+d) x+M \leq I+d h l-T .
$$

$d \in R_{++}$signifies both, the level of deposit and the level of refund given by the government. $T \in R_{+}$signifies the lump-sum tax with which the government covers costs for managing a 
deposit-refund system. We assume that consumers discard or return the containers shortly after the purchase.

Therefore, the Lagrangean is

$$
L=a_{d} x-\frac{1}{2} m_{d} x^{2}-\frac{1}{2} m_{k} h^{2} l^{2}+M-\theta W+\lambda[I+d h l-T-(p+d) x-M]
$$

where $\lambda$ indicates the marginal utility of income. The necessary conditions for the inverse demand function are mentioned below:

$$
\begin{aligned}
& p=a_{d}-m_{d} x-d \\
& I+d y-(p+d) x-M-T=0 .
\end{aligned}
$$

$l$ is equal to $\frac{d}{m_{k} h}$, so that $y$ is equal to $\frac{d}{m_{k}}$ because $y=h l$. This implies that the quantity of returned containers $(y)$ increase as the time and expenses incurred to return the containers $\left(m_{k}\right)$ decreases or as the deposit level $(d)$ increases.

On the other hand, the supplier's profit function depends on the holder of the unredeemed deposits. When holding unredeemed deposits, the supplier considers them as profits. Unredeemed deposits are the difference between aggregate deposits $(d X)$ and aggregate refunds $(d Y)$. Then, the supplier has to deal with the following problem:

$$
\max _{X} \pi(X)=\left[(p+d) X-C_{1}(X)\right]+\left[(\tau-d+f) Y-C_{2}(Y)+\Delta \bar{C}_{2}\right]
$$

The first square bracket indicates the revenue from selling $X$, while the second square bracket indicates that from receiving the containers. $\tau$ is the scrap value per returned container, while $f$ is the handling commission per received container. Previous studies have not considered handling commissions; however, in practice, almost all systems that do not include handling commissions for retailers cannot be sustained. Therefore, it is important to include handling commissions in the deposit-refund system. $Y$ is the aggregate returned quantity, ny. $C_{2}(Y)$ is the cost of handling the containers; it is specified as $\frac{1}{2} m_{s y} Y^{2}+a_{s y} Y+$ $\bar{C}_{2}$, where $m_{s y}>0$ and $a_{s y}>0 . \bar{C}_{2}$ indicates the annualized fixed cost, which includes the cost of developing the system for receiving containers. $\Delta \bar{C}_{2}$ is a subsidy to a fixed cost $\left(\bar{C}_{2}\right)$, which is paid by a government. When a subsidy to a fixed cost is not paid, $\Delta \bar{C}_{2}$ becomes 0. The supplier's decision variable is indicated by $X$, because suppliers, generally, cannot 
refuse to collect containers due to the mandatory deposit legislation.

By differentiating $\pi$ with respect to $X$, the following inverse supply function can be derived:

$$
p=m_{s x} X+a_{s x}-d .
$$

When the government confiscates unredeemed deposits, they are deleted from the profit and the suppliers' problem can be indicated as below:

$$
\max _{X} \pi(X)=\left[p X-C_{1}(X)\right]+\left[(\tau+f) Y-C_{2}(Y)+\Delta \bar{C}_{2}\right] .
$$

Therefore, the necessary condition for the inverse supply function is $p=m_{s x} X+a_{s x}$.

The government must satisfy a revenue neutral constraint. When suppliers hold unredeemed deposits, the government pays the handling commission from a fund created by levying a lump-sum tax, $T$, on the consumer; therefore, the revenue neutral constraint is

$$
f Y+\Delta \bar{C}_{2}=n T .
$$

When the government confiscates unredeemed deposits, the fund for handling commissions is not only a lump-sum tax on the consumer but also unredeemed deposits. Thus, the revenue neutral constraint is

$$
f Y+\Delta \bar{C}_{2}=d(X-Y)+n T
$$

\section{Analysis}

\subsection{Market Equilibrium}

Based on the necessary conditions of a demand and supply function in the model, we derive a market equilibrium for each policy package. Table 2 shows the legends of four policy package. This section focuses on $[2 \mathrm{~A}]$ case wherein suppliers hold unredeemed deposits and 
the handling commission is paid. The necessary conditions can be summarized as follows:

$$
\begin{aligned}
& F_{1}=p-a_{d}+m_{d} x+d=0 \\
& F_{2}=I+d y-(p+d) x-M-T=0 \\
& F_{3}=p-m_{s x} X-a_{s x}+d=0 \\
& F_{4}=y-\frac{d}{m_{k}}=0 \\
& F_{5}=f Y+\Delta \bar{C}_{2}-n T=0
\end{aligned}
$$

When the handling commission is not paid, $f$ is counted as 0 .

If we substitute $F_{4}, F_{5}$, and $F_{6}$ for $F_{1}, F_{2}$, and $F_{3}$ and solve $F_{1}, F_{2}, F_{3}$ with respect to $x, y, p$, and $M$, we acquire the following market equilibrium:

$$
\begin{aligned}
x^{*} & =\frac{a_{d}-a_{s x}}{m_{d}+m_{s x}} \\
y^{*} & =\frac{d}{m_{k}} \\
p^{*} & =\frac{m_{s x}\left(a_{d}-d\right)+m_{d}\left(a_{s x}-d\right)}{m_{d}+m_{s x}} \\
M^{*} & =I+\frac{d^{2}}{m_{k}}-\left(\frac{m_{s x} n\left(a_{d}-d\right)+m_{d}\left(a_{s x}-d\right)}{m_{d}+m_{s x} n}+d\right) \frac{a_{d}-a_{s x}}{m_{d}+m_{s x} n}-\frac{f d}{m_{k}}-\frac{\Delta \bar{C}_{2}}{n} .
\end{aligned}
$$

We elicit market equilibriums for other cases $([2 \mathrm{~B}],[3 \mathrm{~A}]$, and $[3 \mathrm{~B}])$ in a similar manner. We assume $a_{d}-a_{s x}-d>0$ in order to avoid the case in which $x$ becomes negative in [3A] and $[3 \mathrm{~B}]$.

Next, we derive consumer surplus, producer surplus, and social surplus for each case. The consumer surplus is the same as compensated variation or equivalent variation when the utility function is assumed to be quasi-linear. Therefore, we regard consumer surplus as an indication of consumer satisfaction. The method to derive surpluses is indicated in the Appendix 1. Surplus calculation results are shown in the Appendix 2 whose section numbers corresponds to each legend in Table 2. The supplier's resistance alleviating conditions can be attained by setting producer surpluses larger than those before a deposit-refund system, as shown in Table 3 . 


\subsection{Supplier's Resistance Alleviating Effect}

A deposit-refund system is recommended in various studies; however, in practice, this system is hardly realized because of the negative impacts on suppliers. In order to fill the gap between those various studies and practice, it is important to consider the supplier's resistance alleviating policy in a deposit-refund system. Table 3 shows us the condition in each policy package for succeeding in alleviating supplier's resistance.

From the unredeemed deposit viewpoint, we can find two characteristics. One characteristic is that there is a possibility that the confiscation of unredeemed deposits by the government may exacerbate the supplier's resistance to the deposit-refund system. When the government confiscates unredeemed deposits $([3 \mathrm{~A}]$ and $[3 \mathrm{~B}])$, the term

$$
-m_{s x} n^{2} \frac{d}{\left(m_{d}+m_{s x} n\right)^{2}}\left(a_{d}-a_{s x}-\frac{1}{2} d\right)
$$

is added to the condition where unredeemed deposits are kept by suppliers $([2 \mathrm{~A}]$ and $[2 \mathrm{~B}])$. This term is negative because $a_{d}-a_{s x}-\frac{d}{2}$ is positive based on the assumption that $a_{d}-a_{s x}-d$ is positive. Therefore, in this case, the supplier's resistance alleviating condition is harder to realize than in the case where suppliers hold unredeemed deposits. We can make sense of this characteristic because the suppliers' revenue decreases when unredeemed deposits are confiscated by the government. The other characteristic is that the suppliers' resistance alleviating condition in the case where suppliers hold unredeemed deposits $([2 \mathrm{~A}]$ and $[2 \mathrm{~B}])$ is harder to realize by $\frac{d^{2} n}{m_{k}}$ than the condition where the government confiscates unredeemed deposits $([3 \mathrm{~A}]$ and $[3 \mathrm{~B}])$. This term implies that the payment of refund is regarded as cost to suppliers when the unredeemed deposits are counted as suppliers' revenue; however, when unredeeemed deposits are confiscated and not counted as suppliers' revenue, the payment of refund is not regarded as cost to suppliers. Therefore, from the view of supplier's resistance alleviating, if the term (1) is larger than $\frac{d^{2} n}{m_{k}}$, the government confiscating unredeemed deposits excerbates the supplier's resistance.

Concerning to the handling commission policy, as the handling commission increases, the resistance alleviating condition becomes easier to hold. We can check this by differentiating the handling commission payment condition $([2 \mathrm{~A}]$ and $[3 \mathrm{~A}])$ with respect to $f$. 
Viewing from the policy of subsidizing costs for putting collection system in place suggests that the policy to subsidize costs by $\Delta \bar{C}_{2}$ for putting collection systems in place reduces the burden $\bar{C}_{2}$ by that amount.

\subsection{Social Impacts of Resistance Alleviating Policy}

Furthermore, we consider whether a deposit-refund system with the supplier's resistance allaying policies brings about a social improvement when compared to the case before a deposit-refund system. As shown in Table 4, we obtain the conditions in which the supplier's resistance allaying deposit-refund system improves socially, by setting the social surplus of each supplier's resistance alleviating deposit-refund system larger than the social surplus before a deposit-refund system.

There are three kinds of policy implication in each resistance allaying policy as shown in Table 4. Firstly, the government should confiscate unredeemed deposits when a deposit level is set to be equal to externality. This is because the social improving condition when the holder of unredeemed deposits is the government has an additional term compared to the case when the holder of unredeemed deposits is a supplier:

$$
d n \frac{\theta n-\frac{d}{2}}{m_{d}+m_{s x} n} .
$$

In the discussion of a deposit-refund system, a deposit level is often assumed to be equal to externality $(\theta)$ a la Pigou. Because $n$ is assumed to be a positive integer more than one, $\theta n>\frac{d}{2}$ always holds, which results in the term (2) positive. Therefore, the government should confiscate unredeemed deposits from the suppliers. This term (2) comes from the fact that when unredeemed deposits holder is changed from suppliers to the government, the increase of consumer surplus is larger than the decrease of producer surplus. The increase of consumer surplus is brought about by the decrease of deposit-refund goods transacted $(x)$ which leads to the decrease of the waste $(x-y)$. On the other hand, since $x^{*}$ decreases, the producer's surplus decreases so that the suppliers resistance alleviating condition becomes stricter as shown above.

The second implication is related to the policy of a handling commission. It implies 
that it does not matter whether or not a handling commission is paid. This can be found from the fact that the handling commission does not appear in the condition. On the other hand, as shown above, the lower the handling commission is, the more difficult to hold the conditions for supplier's resistance alleviating deposit-refund system are.

Lastly, we have implication for the policy to subsidize a fixed cost. That is to say, it does not matter whether and how much a fixed cost is subsidized. This can be checked from the fact that the term $\Delta \bar{C}_{2}$ also does not appear in the condition. Subsidizing a fixed cost alleviates the burden to producers as shown in Table 3; however, in the model, the consumer pays a lump-sum tax to compensate for the subsidy to a fixed cost. In other words, the subsidy to a fixed cost is a transfer from the consumers to the supplier. As a consequence, the subsidy policy does not affect social surplus.

\section{Conclusion}

There exists a gap between the real-world application of a deposit-refund system and previous studies. The gap originates from the negative impacts caused by the introduction of the system on suppliers. We consider three mitigating policies in the economy, i.e., leaving in the suppliers unredeemed deposits, paying a handling commission to the suppliers, and subsidizing the initial cost for the collection of materials.

This paper theoretically suggests that when a deposit-refund system sets a deposit level that is equal to externality, the government should confiscate unredeemed deposits. However, the negative impacts on suppliers may be exacerbated in this case. This conclusion is arrived at by decreasing the externality, which is obtained by suppressing production when the government confiscates unredeemed deposits. Second, it is of no consequence whether or not the handling commission is paid. However, it does affect the supplier. This implies that whether or not a handling commission is paid has nothing to do with efficiency, but rather with fairness among actors. Third, subsidizing the initial cost for the collection of materials also does not matter, however it is also related to fairness among the consumer and the producer. 
Future studies should consider the cost of treating waste and what percentage of unredeemed deposits should be shared between the government and the supplier. In practice, the waste must be treated costly and unredeemed deposits are sometimes divided into each actor. However, it is difficult to assess the percentage of the waste treatment cost that each actor should bear and the percentage of unredeemed deposits that should be held between the government and the supplier. Adding the waste treatment cost and the unredeemed deposits share among actors to this model should contribute to solving this problem.

Acknowledgements: I am grateful to Kenji Takeuchi, Masanobu Ishikawa, Jun Iritani, Ivan Brenes, Tamotsu Nakamura of Kobe University, Kazuhiro Ueta of Kyoto University, Ayumi Onuma of Keio University, and Hajime Yamakawa of Kyoto Prefectural University for their valuable comments. The former version of this paper was presented in the Japanese Economic Association 2005 Spring Annual Conference on June 4th, 2005 in Kyoto Sangyo University. The responsibility for all mistakes in this paper lies with me.

\section{References}

[1] Bohm P (1981) Deposit-Refund Systems: Theory and Applications to Environmental, Conservation and Consumer Policy. Johns Hopkins University Press

[2] Dobbs I M (1991) Litter and waste management: disposal taxes versus user charges. Canadian Journal of Economics 24:221-227

[3] Atri S and Schellberg T (1995) Efficient management of household solid waste: a general equilibrium model. Public Finance Quarterly 23(1):3-39

[4] Fullerton D and Kinnaman T (1995) Garbage, Recycling, and Illicit Burning or Dumping. J Environ Econ Manag 29:78-91

[5] Lee D R, Graves P E, Sexton R L (1992) Controlling the Abandonment of Automobiles: Mandatory Deposits vs Fines. J Urban Econ 31:14-24 
[6] Palmer K, Sigman H, Walls M (1997) The Cost of Reducing Municipal Solid Waste. J Environ Econ Manag 33:128-150

[7] Fullerton D and Wu W (1998) Policies for Green Design. J Environ Econ Manag $36(2): 131-148$

[8] Calcott P and Walls M (2000) Policies to Encourage Recycling and "Design for Environment" : What to Do When Markets are Missing. Resources for the Future Discussion Paper 00-30

[9] Kansai Council (2003) Proposal about system to collect container waste (in Japanese). Kansai Council, Osaka

[10] Onuma A and Saito T (2003) Some Effects of Deposit-Refund System on Producers and Consumers. Keio University Discussion Paper No.03-5

[11] Palmer K and Walls M (1997) Optimal policies for solid waste disposal Taxes, subsidies, and standards. J Publ Econ 65:193-205

[12] Fullerton D and Wolverton A (1999) The Case for a Two-Part Instrument: Presumptive Tax and Environmental Subsidy. In: Panagariya A, Portney PR, Schwab RM (eds) Environmental and Public Economics: Essays in Honor of Wallace E. Oates. Edward Elgar Publishing Ltd, Cheltenham, 32-57

[13] Walls M and Palmer K (2000) Upstream Pollution, Downstream Waste Disposal, and the Design of Comprehensive Environmental Policies. Resources for the Future Discussion Paper 97-51

[14] Sigman, H (1995) A comparison of public policies for lead recycling. Rand J Econ $26(3): 452-478$

[15] Mrozek, J R (2000) Revenue Neutral Deposit/Refund Systems. Environ Resource Econ $17: 183-193$

[16] Porter R (2002) The Economics of Waste. Resources for the Future Press 
Figure. 1

A Model Concept of the Case wherein Suppliers Hold Unredeemed Deposits

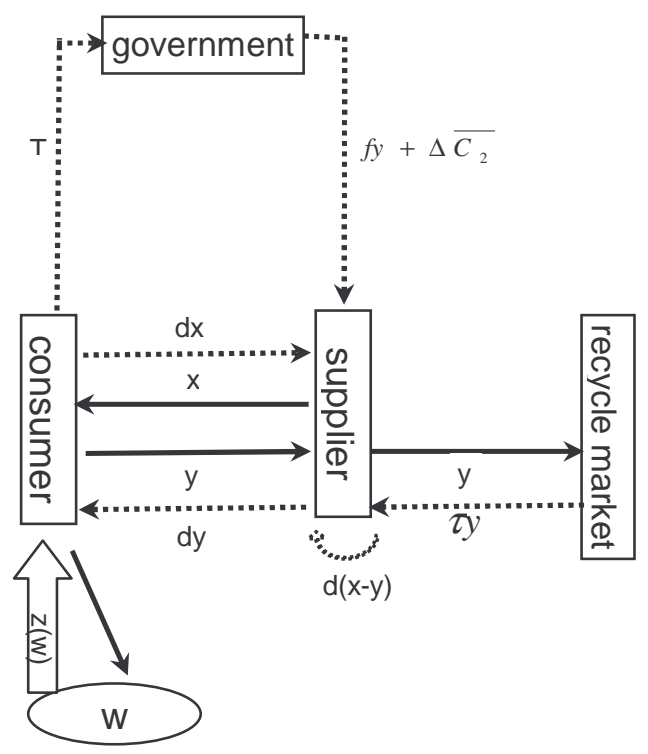

...............> Money Flow

$\rightarrow$ Material Flow 
Figure. 2

A Model Concept of the Case wherein the Government Confiscates Unredeemed Deposits

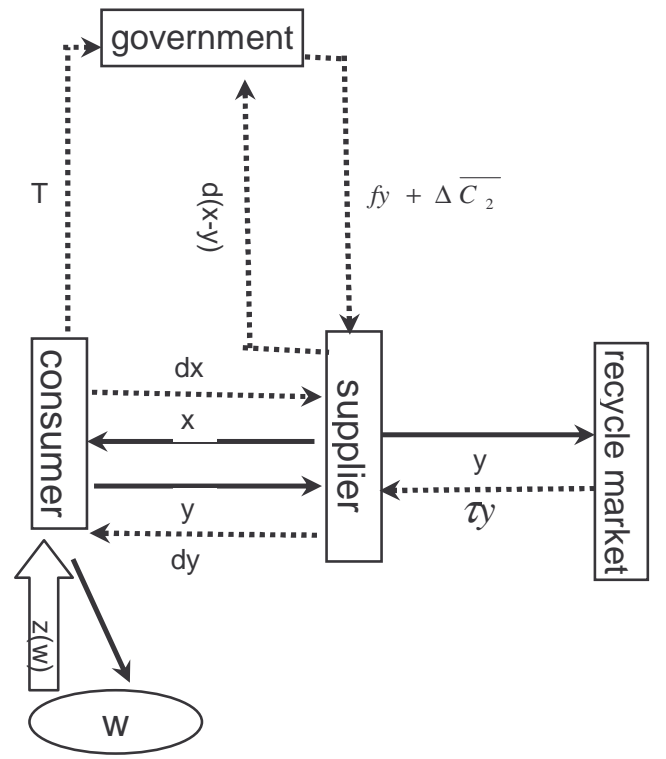

............... Money Flow Material Flow 
Table 1: Classification of the Present Practical Examples of Deposit-Refund System in North America and Japan

\begin{tabular}{|c|c||c|c|}
\hline \multicolumn{2}{|c||}{} & \multicolumn{2}{c|}{ Handling Commission } \\
\cline { 2 - 4 } Deposits & \multirow{2}{*}{ Unredeemed } & Paid & Not Paid \\
\cline { 2 - 4 } Holder & Gotiers & Not Available & $\begin{array}{c}\text { Iowa, Delaware } \\
\text { Conneticut, New York } \\
\text { Vermont, Oregon }\end{array}$ \\
\cline { 2 - 4 } & Government & $\begin{array}{c}\text { Himeshima Oita } \\
\text { Alberta } \\
\text { British Columbia }\end{array}$ & $\begin{array}{c}\text { California, Hawaii, Michigan } \\
\text { Massachusetts, Maine }\end{array}$ \\
\hline
\end{tabular}

Table 2: Legend of Policy Package

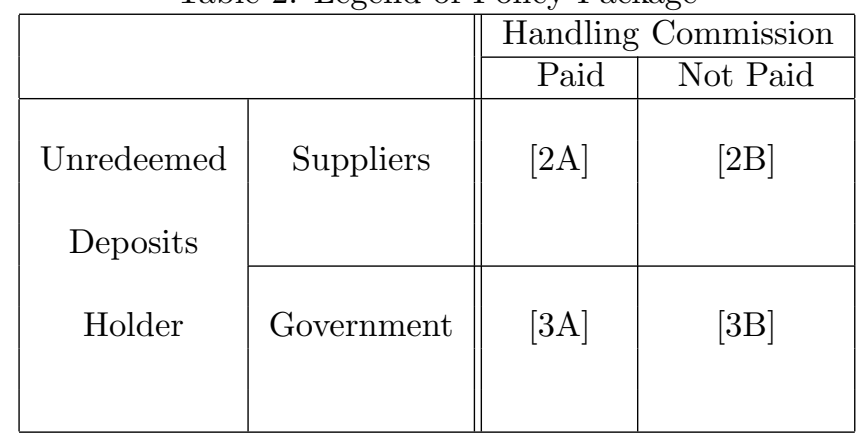




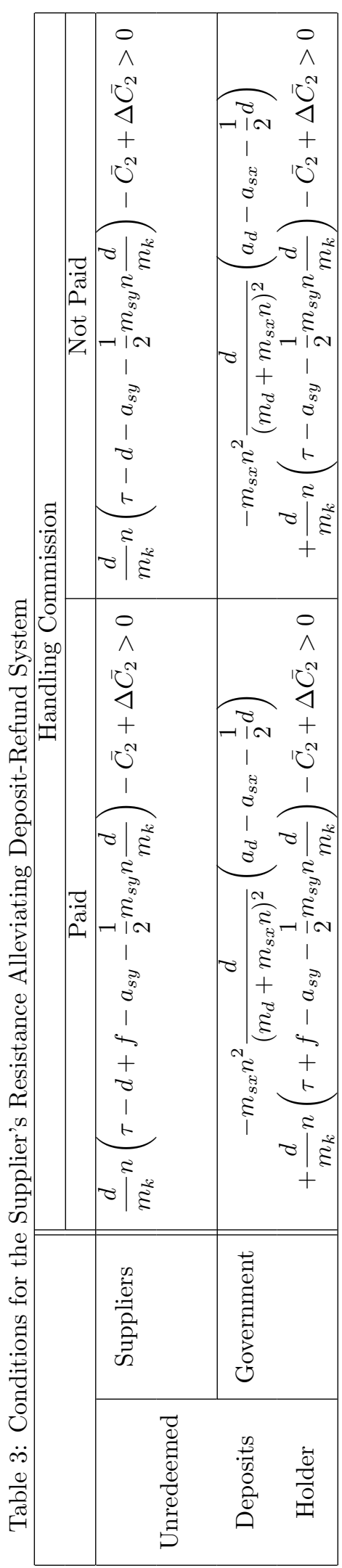




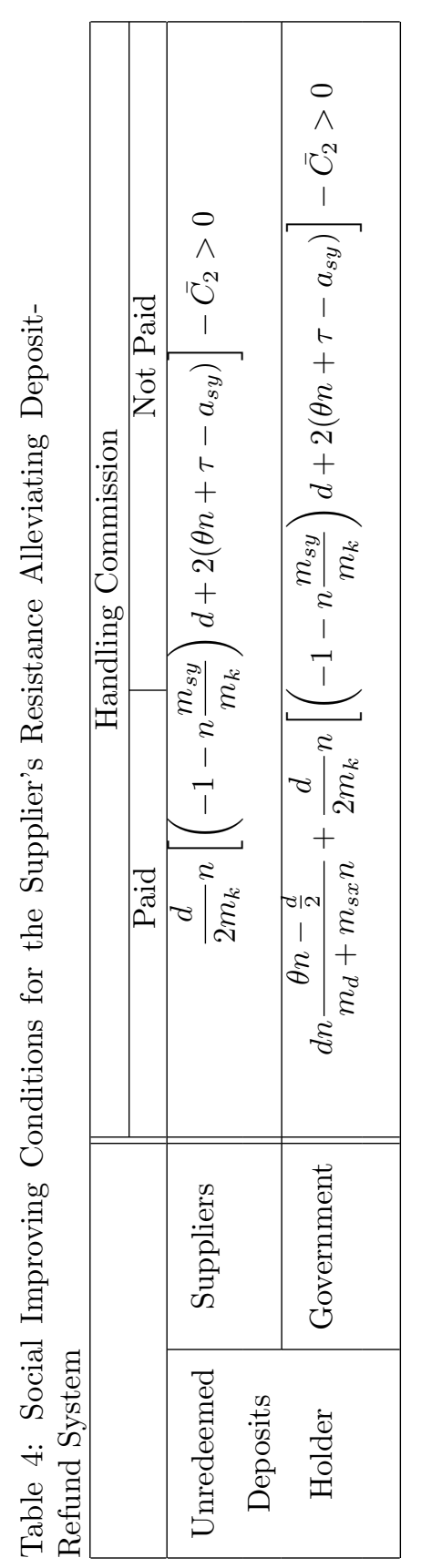




\section{Appendix 1: Surplus Calculation}

We show the method to derive surpluses using the case in which, a deposit-refund system is introduced, the unredeemed deposits holder is the supplier, the handling commission is paid and the initial cost is subsidized. The case in which the handling commission is not paid is derived by substituting 0 for $f$, and the case in which the initial cost is not subsidized is also derived by substituting 0 for $\Delta \bar{C}_{2}$.

\subsection{Market Equilibrium}

The necessary conditions of the market can be summarized as follows:

$$
\begin{aligned}
& F_{1}=p-a_{d}+m_{d} x+d=0 \\
& F_{2}=I+d y-(p+d) x-M-T=0 \\
& F_{3}=p-m_{s x} X-a_{s x}+d=0 \\
& F_{4}=y-\frac{d}{m_{k}}=0 \\
& F_{5}=f Y+\Delta \bar{C}_{2}-n T=0
\end{aligned}
$$

Substitute $F_{4}$ and $F_{5}$ for $F_{1}, F_{2}$, and $F_{3}$

$$
\begin{aligned}
& F_{1}=p-a_{d}+m_{d} x+d=0 \\
& F_{2}=I+\frac{d^{2}}{m_{k}}-(p+d) x-M-\frac{f d}{m_{k}}-\frac{\Delta \bar{C}_{2}}{n}=0 \\
& F_{3}=p-m_{s x} X-a_{s x}+d=0
\end{aligned}
$$

Then, considering $X=n x$, the market equilibrium can be described as follows:

$$
\begin{aligned}
x^{*} & =\frac{a_{d}-a_{s x}}{m_{d}+m_{s x} n} \\
y^{*} & =\frac{d}{m_{k}} \\
p^{*} & =\frac{m_{s x} n\left(a_{d}-d\right)+m_{d}\left(a_{s x}-d\right)}{m_{d}+m_{s x} n} \\
M^{*} & =I+\frac{d^{2}}{m_{k}}-\left(\frac{m_{s x} n\left(a_{d}-d\right)+m_{d}\left(a_{s x}-d\right)}{m_{d}+m_{s x} n}+d\right) \frac{a_{d}-a_{s x}}{m_{d}+m_{s x} n}-\frac{f d}{m_{k}}-\frac{\Delta \bar{C}_{2}}{n}
\end{aligned}
$$




\subsection{Consumer Surplus}

The representative consumer surplus (CS) is derived by the difference between the utility when $x, y$, and $M$ are transacted and the utility when they are not transacted.

$$
\begin{aligned}
C S= & U\left(x^{*}, y^{*}, M^{*}\right)-U(0,0, I) \\
= & {\left[a_{d} x^{*}-\frac{1}{2} m_{d} x^{* 2}-\frac{1}{2} m_{k} y^{* 2}+M^{*}-\theta n\left(x^{*}-y^{*}\right)\right] } \\
& \quad-\left[a_{d} \times 0-\frac{1}{2} m_{d} \times 0^{2}-\frac{1}{2} m_{k} \times 0^{* 2}+I-\theta n(0-0)\right] \\
= & a_{d} \frac{a_{d}-a_{s x}}{m_{d}+m_{s x} n}-\frac{1}{2} m_{d}\left(\frac{a_{d}-a_{s x}}{m_{d}+m_{s x} n}\right)^{2}-\frac{1}{2} m_{k}\left(\frac{d}{m_{k}}\right)^{2} \\
& \quad+I+\frac{d^{2}}{m_{k}}-\left(\frac{m_{s x} n\left(a_{d}-d\right)+m_{d}\left(a_{s x}-d\right)}{m_{d}+m_{s x} n}+d\right) \frac{a_{d}-a_{s x}}{m_{d}+m_{s x} n}-\frac{f d}{m_{k}}-\frac{\Delta \bar{C}_{2}}{n} \\
& \quad-\theta n\left(\frac{a_{d}-a_{s x}}{m_{d}+m_{s x} n}-\frac{d}{m_{k}}\right)-I \\
= & \frac{a_{d}-a_{s x}}{m_{d}+m_{s x} n}\left(\frac{\frac{1}{2} m_{d}\left(a_{d}-a_{s x}\right)}{m_{d}+m_{s x} n}-\theta n\right)+\frac{d(d-2 f+2 \theta n)}{2 m_{k}}-\frac{\Delta \bar{C}_{2}}{n}
\end{aligned}
$$

\subsection{Producer Surplus}

The producer surplus (PS) is derived by the difference between the profit when $x, y$, and $M$ are transacted and the profit when they are not transacted.

$$
\begin{aligned}
P S= & \pi\left(n x^{*}\right)-\pi(0) \\
= & {\left[\left(p^{*}+d\right) n x^{*}-\frac{1}{2} m_{s x} n^{2} x^{* 2}-a_{s x} n x^{*}-\bar{C}_{1}\right]+\left[(\tau-d+f) n y^{*}-\frac{1}{2} m_{s y} n^{2} y^{* 2}-a_{s y} n y^{*}-\bar{C}_{2}+\Delta \bar{C}_{2}\right] } \\
& \quad-\left\{\left[\left(p^{*}+d\right) \times 0-\frac{1}{2} m_{s x} \times 0^{2}-a_{s x} \times 0-\bar{C}_{1}\right]+\left[(\tau-d+f) \times 0-\frac{1}{2} m_{s y} \times 0^{2}-a_{s y} \times 0\right]\right\} \\
= & \left(p+d-a_{s x}\right) n x^{*}-\frac{1}{2} m_{s x} n^{2} x^{* 2}+\left(\tau-d+f-a_{s y}\right) n y^{*}-\frac{1}{2} m_{s y} n^{2} y^{* 2}-\bar{C}_{2}+\Delta \bar{C}_{2} \\
= & \left(\frac{m_{s x} n\left(a_{d}-d\right)+m_{d}\left(a_{s x}-d\right)}{m_{d}+m_{s x} n}+d-a_{s x}\right) n \frac{a_{d}-a_{s x}}{m_{d}+m_{s x} n}-\frac{1}{2} m_{s x} n^{2}\left(\frac{a_{d}-a_{s x}}{m_{d}+m_{s x} n}\right)^{2} \\
& \quad+\left(\tau-d+f-a_{s y}\right) n \frac{d}{m_{k}}-\frac{1}{2} m_{s y} n^{2} \frac{d^{2}}{m_{k}^{2}}-\bar{C}_{2}+\Delta \bar{C}_{2} \\
= & \frac{1}{2} m_{s x} n^{2}\left(\frac{a_{d}-a_{s x}}{m_{d}+m_{s x} n}\right)^{2}+\frac{d}{m_{k}} n\left(\tau-d+f-a_{s y}-\frac{1}{2} m_{s y} n \frac{d}{m_{k}}\right)-\bar{C}_{2}+\Delta \bar{C}_{2}
\end{aligned}
$$




\subsection{Social Surplus}

The social surplus (SS) is derived by adding the $n$ consumers' surpluses to the producer's surplus above.

$$
\begin{aligned}
& S S=n C S+P S \\
&=n\left\{\frac{a_{d}-a_{s x}}{m_{d}+m_{s x} n}\left(\frac{\frac{1}{2} m_{d}\left(a_{d}-a_{s x}\right)}{m_{d}+m_{s x} n}-\theta n\right)+\frac{d(d-2 f+2 \theta n)}{2 m_{k}}-\frac{\Delta \bar{C}_{2}}{n}\right\} \\
&+\frac{1}{2} m_{s x} n^{2}\left(\frac{a_{d}-a_{s x}}{m_{d}+m_{s x} n}\right)^{2}+\frac{d}{m_{k}} n\left(\tau-d+f-a_{s y}-\frac{1}{2} m_{s y} n \frac{d}{m_{k}}\right)-\bar{C}_{2}+\Delta \bar{C}_{2} \\
&=\left(\frac{a_{d}-a_{s x}}{m_{d}+m_{s x}}\right)^{2}\left(\frac{1}{2} n m_{d}+\frac{1}{2} m_{s x} n^{2}\right)-\theta n^{2} \frac{a_{d}-a_{s x}}{m_{d}+m_{s x}} \\
&+\frac{d}{2 m_{k}} n\left[\left(-1-\frac{2 m_{s y}}{m_{k}} n\right) d+2\left(\theta n+\tau-a_{s y}\right)+\frac{m_{s y}}{m_{k}} d n\right]-\bar{C}_{2} \\
&=\left.\frac{a_{d}-a_{s x}}{m_{d}+m_{s x}}\right)^{2}\left[\frac{1}{2} n\left(m_{d}+m_{s x} n\right)\right]-\theta n^{2} \frac{a_{d}-a_{s x}}{m_{d}+m_{s x}} \\
&+\frac{d}{2 m_{k}} n\left[\left(-1-\frac{m_{s y}}{m_{k}} n\right) d+2\left(\theta n+\tau-a_{s y}\right)\right]-\bar{C}_{2}
\end{aligned}
$$

\section{Appendix2: Surplus Calculation Result}

\section{Before Deposit-Refund System}

$$
\begin{aligned}
C S & =\frac{a_{d}-a_{s x}}{m_{d}+m_{s x} n}\left(\frac{\frac{m_{d}}{2}\left(a_{d}-a_{s x}\right)}{m_{d}+m_{s x} n}-\theta n\right) \\
P S & =\frac{1}{2} m_{s x} n^{2}\left(\frac{a_{d}-a_{s x}}{m_{d}+m_{s x} n}\right)^{2} \\
S S & =\left(\frac{a_{d}-a_{s x}}{m_{d}+m_{s x}}\right)^{2}\left[\frac{1}{2} n\left(m_{d}+m_{s x} n\right)\right]-\theta n^{2} \frac{a_{d}-a_{s x}}{m_{d}+m_{s x}}
\end{aligned}
$$




\section{A. After Deposit-Refund System}

The Unredeemed Deposits Holder is the Supplier and The Handling Commission is Paid

$$
\begin{aligned}
C S= & \frac{a_{d}-a_{s x}}{m_{d}+m_{s x} n}\left(\frac{\frac{1}{2} m_{d}\left(a_{d}-a_{s x}\right)}{m_{d}+m_{s x} n}-\theta n\right)+\frac{d(d-2 f+2 \theta n)}{2 m_{k}}-\frac{\Delta \bar{C}_{2}}{n} \\
P S= & \frac{1}{2} m_{s x} n^{2}\left(\frac{a_{d}-a_{s x}}{m_{d}+m_{s x} n}\right)^{2}+\frac{d}{m_{k}} n\left(\tau-d+f-a_{s y}-\frac{1}{2} m_{s y} n \frac{d}{m_{k}}\right)-\bar{C}_{2}+\Delta \bar{C}_{2} \\
S S= & \left(\frac{a_{d}-a_{s x}}{m_{d}+m_{s x}}\right)^{2}\left[\frac{1}{2} n\left(m_{d}+m_{s x} n\right)\right]-\theta n^{2} \frac{a_{d}-a_{s x}}{m_{d}+m_{s x}} \\
& \quad+\frac{d}{2 m_{k}} n\left[\left(-1-n \frac{m_{s y}}{m_{k}}\right) d+2\left(\theta n+\tau-a_{s y}\right)\right]-\bar{C}_{2}
\end{aligned}
$$

\section{B. After Deposit-Refund System}

The Unredeemed Deposits Holder is the Supplier and The Handling Commission is Not Paid

$$
\begin{aligned}
C S= & \frac{a_{d}-a_{s x}}{m_{d}+m_{s x} n}\left(\frac{\frac{1}{2} m_{d}\left(a_{d}-a_{s x}\right)}{m_{d}+m_{s x} n}-\theta n\right)+\frac{d(d+2 \theta n)}{2 m_{k}}-\frac{\Delta \bar{C}_{2}}{n} \\
P S= & \frac{1}{2} m_{s x} n^{2}\left(\frac{a_{d}-a_{s x}}{m_{d}+m_{s x} n}\right)^{2}+\frac{d}{m_{k}} n\left(\tau-d-a_{s y}-\frac{1}{2} m_{s y} n \frac{d}{m_{k}}\right)-\bar{C}_{2}+\Delta \bar{C}_{2} \\
S S= & \left(\frac{a_{d}-a_{s x}}{m_{d}+m_{s x}}\right)^{2}\left[\frac{1}{2} n\left(m_{d}+m_{s x} n\right)\right]-\theta n^{2} \frac{a_{d}-a_{s x}}{m_{d}+m_{s x}} \\
& +\frac{d}{2 m_{k}} n\left[\left(-1-n \frac{m_{s y}}{m_{k}}\right) d+2\left(\theta n+\tau-a_{s y}\right)\right]-\bar{C}_{2}
\end{aligned}
$$

\section{A. After Deposit-Refund System}

The Unredeemed Deposits Holder is the Government and The Handling Commission is Paid

$$
\begin{aligned}
C S= & \frac{a_{d}-a_{s x}}{m_{d}+m_{s x} n}\left[\frac{\frac{1}{2} m_{d}\left(a_{d}-a_{s x}\right)}{m_{d}+m_{s x} n}-\theta n\right]+d \frac{m_{s x} n\left(a_{d}-a_{s x}-d+\theta n\right)+m_{d}\left(-\frac{d}{2}+\theta n\right)}{\left(m_{d}+m_{s x} n\right)^{2}} \\
& +\frac{d}{2 m_{k}}[-d+2(\theta n)]-\frac{\Delta \bar{C}_{2}}{n} \\
P S= & \frac{1}{2} m_{s x} n^{2}\left(\frac{a_{d}-a_{s x}}{m_{d}+m_{s x} n}\right)^{2}-m_{s x} n^{2} \frac{d}{\left(m_{d}+m_{s x} n\right)^{2}}\left(a_{d}-a_{s x}-\frac{1}{2} d\right) \\
& +\frac{d}{m_{k}} n\left(\tau-a_{s y}-\frac{1}{2} m_{s y} n \frac{d}{m_{k}}\right)-\bar{C}_{2}+\Delta \bar{C}_{2} \\
S S= & \left.\quad \frac{a_{d}-a_{s x}}{m_{d}+m_{s x} n}\right)^{2}\left[\frac{1}{2} n\left(m_{d}+m_{s x} n\right)\right]-\theta n^{2} \frac{a_{d}-a_{s x}}{m_{d}+m_{s x} n}+d n \frac{\theta n-\frac{1}{2} d}{m_{d}+m_{s x}} \\
& +\frac{d n}{2 m_{k}}\left[\left(-1-\frac{m_{s y}}{m_{k}} n\right) d+2\left(\theta n+\tau-a_{s y}\right)\right]-\bar{C}_{2}
\end{aligned}
$$




\section{B.After Deposit-Refund System}

The Unredeemed Deposits Holder is the Government and The Handling Commission is Not Paid

$$
\begin{aligned}
C S= & \frac{a_{d}-a_{s x}}{m_{d}+m_{s x} n}\left[\frac{\frac{1}{2} m_{d}\left(a_{d}-a_{s x}\right)}{m_{d}+m_{s x} n}-\theta n\right]+d \frac{m_{s x} n\left(a_{d}-a_{s x}-d+\theta n\right)+m_{d}\left(-\frac{d}{2}+\theta n\right)}{\left(m_{d}+m_{s x} n\right)^{2}} \\
& +\frac{d}{2 m_{k}}[-d+2(\theta n-f)]-\frac{\Delta \bar{C}_{2}}{n} \\
P S= & \frac{1}{2} m_{s x} n^{2}\left(\frac{a_{d}-a_{s x}}{m_{d}+m_{s x} n}\right)^{2}-m_{s x} n^{2} \frac{d}{\left(m_{d}+m_{s x} n\right)^{2}}\left(a_{d}-a_{s x}-\frac{1}{2} d\right) \\
& +\frac{d}{m_{k}} n\left(\tau+f-a_{s y}-\frac{1}{2} m_{s y} n \frac{d}{m_{k}}\right)-\bar{C}_{2}+\Delta \bar{C}_{2} \\
S S= & \left.\quad \frac{a_{d}-a_{s x}}{m_{d}+m_{s x} n}\right)^{2}\left[\frac{1}{2} n\left(m_{d}+m_{s x} n\right)\right]-\theta n^{2} \frac{a_{d}-a_{s x}}{m_{d}+m_{s x} n}+d n \frac{\theta n-\frac{1}{2} d}{m_{d}+m_{s x}} \\
& +\frac{d n}{2 m_{k}}\left[\left(-1-\frac{m_{s y}}{m_{k}} n\right) d+2\left(\theta n+\tau-a_{s y}\right)\right]-\bar{C}_{2}
\end{aligned}
$$

